\title{
Stratified randomisation: a hidden form of clustering?
}

\author{
Brennan C Kahan ${ }^{*}$, Tim P Morris \\ From Clinical Trials Methodology Conference 2011 \\ Bristol, UK. 4-5 October 2011
}

\section{Objectives}

Many randomised trials use stratified permuted blocks or minimisation to balance key prognostic variables between treatment groups. It is widely argued in the statistical literature that any balancing variables should be adjusted for in the analysis, however a review of major medical journals shows that this is not commonly done. Our objective was to determine the effects of an unadjusted analysis after balancing.

\section{Methods}

The statistical properties of an unadjusted analysis after balancing are explored using theoretical results. A major simulation study using data from 5 trials is performed to determine the potential impact in real life situations.

\section{Results}

We show that balancing on baseline covariates leads to correlation between the treatment groups (similarly, cluster randomised trials lead to correlation within treatment groups). If this correlation is ignored, and an unadjusted analysis is performed, the estimated variance of the treatment effect will be biased upwards, resulting in type I error rates that are too low, and a reduction in power. Conversely, an adjusted analysis results in nominal type I error rates, and optimal power.

\section{Conclusions}

Prognostic variables that have been balanced between treatment groups in the randomisation process should be adjusted for in the analysis. Unadjusted analyses lead to invalid results, whereas adjusted analyses maintain nominal properties.

MRC Clinical Trials Unit, 125 Kingsway, London, WC2B 6NH, UK
Published: 13 December 2011

doi:10.1186/1745-6215-12-S1-A22

Cite this article as: Kahan and Morris: Stratified randomisation: a hidden form of clustering? Trials 2011 12(Suppl 1):A22.
Submit your next manuscript to BioMed Central and take full advantage of:

- Convenient online submission

- Thorough peer review

- No space constraints or color figure charges

- Immediate publication on acceptance

- Inclusion in PubMed, CAS, Scopus and Google Scholar

- Research which is freely available for redistribution

\section{Biomed Central}

\section{Biomed Central}

